\title{
Active optical sensing of canopies in pasture management
}

\author{
J. ROBERTS ${ }^{1}$, A. SUAREZ INFIESTA ${ }^{1}$, B. SCHÄBITZ ${ }^{2}$, J. FOURIE ${ }^{1}$ and A. WERNER ${ }^{1}$ \\ ${ }^{1}$ Lincoln Agritech, Lincoln, New Zealand \\ ${ }^{2}$ Agri Con Gmbh, Ostrau, Germany \\ jess.roberts@lincolnagritech.co.nz
}

\begin{abstract}
Commercial units of Active Optical Sensor (AOS) systems are designed for sensing arable crops to estimate the required amount of nitrogen fertiliser and are well established in intensive arable cropping systems in Europe. A research version AOS (RU-AOS) of a commercial system was tested as a potential canopy sensor for New Zealand dairy pastures. To study the applicability of this sensor a sensitivity experiment was conducted. Additionally, a plot experiment investigated the relationship between the spectrometer and biomass attributes on ryegrass and white clover canopies fertilised with five different nitrogen amounts. The pasture plots were sensed with the RU-AOS and results compared with measured biomass dry matter and nitrogen amount. For some events a strong linear relationship between dry matter (DM) and the water index (WI) was evident (i.e. $\mathrm{r}^{2}=0.80$ ) as well as between nitrogen $(\mathrm{N})$ amount and simple ratio (SR) (i.e. $\mathrm{r}^{2}=0.89$ ). The results suggest there is potential for this sensor to estimate New Zealand dairy pasture attributes. This could be used to develop a pasture system similar to commercial arable cropping nitrogen sensor AOSs.
\end{abstract}

Keywords: Active Optical Sensor; pasture; nitrogen

\section{Introduction}

\section{Active Optical Sensing of canopies}

Proximal 'Active Optical Sensing' utilises close range (within a few metres) measurement of light reflectance characteristics from plant canopies. An active optical sensor (AOS) emits light onto the target, allowing the tool to be used independently of ambient light (Yule \& Pullanagari 2009; Erdle et al. 2011). Indices calculated from such reflectance data are used to estimate specific biomass attributes of that crop canopy (Holland \& Schepers 2013; Kim et al. 2012). Commercial AOS systems are available for directing the amount of nitrogen fertiliser applied across a field (Erdle et al. 2011; Heege et al. 2008). These systems are developed and established for arable farming of various crops (Bragagnolo et al. 2013; Roberts et al. 2009; Portz et al. 2012). Examples are the CropCircle ${ }^{\mathrm{TM}}$ (Holland \& Schepers 2013), the Greenseeker ${ }^{\mathrm{TM}}$ (Stone et al. 2003) and the YARA N-Sensor ${ }^{\mathrm{TM}}$ ALS (Jasper et al. 2009). These sensor systems calculate reflection indices at specific wavelengths of reflection from the plant canopy. These indices can be converted automatically or manually into site specific rates of nitrogen fertiliser based on calibration curves provided from research (Link et al. 2003). This kind of sensing system is available for arable cropping, but it is not used for directing fertiliser application in grazed pasture systems.

While not commercial tools, AOSs are successfully used for pasture research to monitor key parameters such as biomass dry matter (DM) (Barnes et al. 2011; Trotter et al. 2010) or plant nitrogen content (Pullanagari et al. 2011). As such, it may be possible to adapt an established AOS to monitor the N-content of, or amount in, a pasture and in turn, to provide an indication of N-requirement across a paddock. This paper outlines the use of a research AOS (RU-AOS) based on the YARA N-Sensor ${ }^{\mathrm{TM}}$ technology to monitor pasture DM and $\mathrm{N}$.

\section{Assessment of canopy characteristics}

The two most common plant attribute indices that can be calculated from reflectance information provided by this AOS are the water index, $W I=\frac{\mathrm{R} 970}{\mathrm{R} 900}$ where " $\mathrm{R}$ " is the reflection wave length (Jackson et al. 2004) and the simple ratio, $S R=\frac{R 760}{R 730}($ Jordan 1969). Several studies have discovered different potential means of using the WI and the SR (Penuelas et al. 1997; Erdle, et al. 2011; Kipp et al. 2012). The WI has been found to correlate to plant water content. The SR has been successfully used to predict yield parameters of crops such as dry matter content, shoot dry weight, fresh matter yield, $\mathrm{N}$ content and above ground $\mathrm{N}$ uptake (Kipp et al. 2012).

There are several attributes of grazed pastures which complicate the process of variable rate application (VRA) of fertiliser directed by AOS in comparison to their proven ability in arable crops. For example, pasture systems are, often desirably, species diverse, as opposed to commonly seen mono-species canopies of crop production. Additionally, non-fertiliser nitrogen inputs can occur through the presence of nitrogenfixing legumes and animal excreta.

A plot experiment was designed to investigate the relationship between the two indices (WI and SR) produced by the RU-AOS spectrometer and manually assessed biomass attributes of a New Zealand dairy pasture. This experiment is a pilot study of the potential to adapt a sensor developed to inform VRA of nitrogen fertiliser in arable crops, for use in pastures. 


\section{Methods}

\section{Experiment site}

Forty pasture plots $(1.5 \mathrm{~m} \times 8 \mathrm{~m})$ were established as model of an intensive rotational grazing system in dairy production in spring, 2012 on Lincoln University Research Dairy farm in Lincoln, New Zealand (Malcolm et al. 2014). The experiment consisted of two sward types; ryegrass monocultures and mixed swards with ryegrass and white clover. Additionally, plots were treated with different amounts of $\mathrm{N}$-fertiliser (urea at $0,46,92,184,368 \mathrm{~kg} \mathrm{~N} /$ ha/year). The total nitrogen amount was divided into ten even portions and applied over ten events, shortly after each harvest. Manual harvest of the plots simulated grazing events. No animal excreta were applied and pasture was irrigated according to demand. The range of fertiliser treatments enabled sensing across a large range in biomass dry matter (DM) and nitrogen content. The plots were arranged in a split-plot design with four replicate blocks containing a strip of each ryegrass and mixed swards in each plot, giving a total of 40 plots, 20 mixed, 20 pure ryegrass and four replications of each fertiliser treatment.

\section{Biomass harvesting}

Management of the plots was designed to reflect standard New Zealand pasture-based dairying practice (McCall et al. 1999). Canopy sensing and biomass harvest occurred when the ryegrass only plots fertilised at the rate of $184 \mathrm{~kg} \mathrm{~N} / \mathrm{ha} /$ year reached approximately $3000 \mathrm{~kg} \mathrm{DM} / \mathrm{ha}$. Biomass was harvested down to an approximated biomass residue of $1600 \mathrm{~kg} \mathrm{DM} / \mathrm{ha}$ (through mowing to $4 \mathrm{~cm}$ canopy height). The harvesting process consisted of first cutting two quadrats $(50 \mathrm{~cm}$ $\times 50 \mathrm{~cm}$ ) per plot. These samples were dissected into green grass, green clover, other and dead material. Wet weight of the portions was recorded and the samples were dried at $68^{\circ} \mathrm{C}$ for between 24 and 48 hours, before dry weights were recorded. Dried samples were finely ground and analysed for total $\mathrm{N}$ concentration using an Elementar Vario-Max CN Elemental Analyser (Elementar GmbH, Hanau, Germany) (Malcolm et al. 2014). After quadrat sampling the remaining plot area was mown to the same height.

\section{Canopy sensing}

An active optical reflectance spectrometer was provided as a research unit (RU-AOS) by YARA GmbH Germany (Jasper \& Reusch pers. comm. 2012). This spectrometer includes a xenon flash light that emits light in a range between 650 to $1100 \mathrm{~nm}$ onto the canopy (Erdle et al. 2011) and offers reflectance data from four optically filtered wavelength channels (730, 760, 900, $970 \mathrm{~nm})$.

Plot reflectance was measured with the RU-AOS spectrometer which was set to record reflectance values once a second. The sensor was mounted on an AllTerrain Vehicle with a sensor view of 40 degrees from nadir and a height of $87 \mathrm{~cm}$ above pasture to ensure the footprint aligned to our plots. The sensor was moved along the long axis of the plots at a speed of approximately $3 \mathrm{~km} /$ hour.

Plot spectrometer results (averaged over the core plot length of $7.5 \mathrm{~m}$ ) were correlated with plot biomass $\mathrm{DM}$ and $\mathrm{N}$-amount $(\mathrm{kg} \mathrm{N} / \mathrm{ha})$. A linear relationship was investigated between WI and DM, as well as SR and $\mathrm{N}$-amount using Microsoft Excel ${ }^{\mathrm{TM}}$. Additionally, the effect of the two sward types on the spectrometer results was investigated.

Biomass sensor analysis and harvesting occurred on five events, with biomass harvesting occurring within 2 days of biomass sensing. The dates of the events were as follows: event $1=24$ March 2014, $2=1$ May 2014, $3=18$ June 2014, $4=26$ August 2014, $5=7$ November 2014.

\section{Sensor angle sensitivity study}

In reviewing the results from the sensing experiment, we determined that the sensor angle could influence our results. Therefore, we investigated the relationship between sensor angle and the relationship between the indices and biomass attributes.

In cropping scenarios, the YARA N-Sensor ${ }^{\mathrm{TM}}$ is mounted at 60 degrees from nadir at a height of around $3 \mathrm{~m}$. Due to plot size restrictions for the reported experiment, the RU-AOS was set at a lower height and angle than used in cropping. To determine if this may have a significant effect on the reflectance results, a sensitivity analysis was conducted.

This experiment was undertaken at the same location outlined above. The RU-AOS sensor was mounted on a pole at two different view angles 55 degrees and 40 degrees (from nadir) and at respective heights of 1.64 $\mathrm{m}$ and $1.58 \mathrm{~m}$ above the canopy. Two sets of sensor readings from a stationary position were taken per plot, one set from each end (short axis) of the plot allowing opposing view directions.

To analyse the influence of the different view angles interacting with the different nitrogen fertilisation levels and the two sward types (including the random effects of block and strip), a split plot ANOVA was conducted (Verzani 2014) with the open source statistics software $\mathrm{R}$, version 3.1.0 (R Development Core Team, 2015). If necessary, the data were transformed using square root or logarithm transformation to fulfil required variance homogeneity.

\section{Results}

Assessing canopy characteristics with the RU-AOS The linear relationship of WI and biomass DM for each event is presented in Table 1, by sward type. Except 
for event 5 , no linear relationship between the index and the biomass was evident, with all coefficients of determination $\left(\mathrm{r}^{2}\right)$ less than 0.5 except for event 5 , in which it was 0.8 for the mixed swards and combined swards. The results of the grass swards had an $r^{2}$ of more than 0.72 for 3 of the 5 events. When data of all events are combined the $r^{2}$ is very low for all sward types $(<0.40)$.

For event 5, the linear relationship between dry matter and water index (measured by the RU-AOS) is displayed in Figure 1, by mixed and grass swards. The mixed sward resulted in a higher $\mathrm{r}^{2}$ for the WI and biomass DM (0.80), although the result for the grass only sward is similar $(0.76)$. When both sward types are combined, the $r^{2}$ is equivalent to that of the mixed sward (0.80).

The results for testing the linear relationship of biomass $\mathrm{N}$-amount and SR for each event are presented in Table 2, by sward type. The combined analysis of sward types (Combined) had a very weak linear relationship for events 1 and 2, however the $\mathrm{r}^{2}$ was above 0.50 for the other three events, with events 4 and 5 showing the highest result ( 0.81 and 0.72 respectively) (Figure 2). The mixed sward plots consistently had the lowest $\mathrm{r}^{2}$ for the relationship between SR and N-amount. As for combined swards, the highest results were for events 4 and 5. For all events, ryegrass swards showed a moderate to strong relationship $\left(\mathrm{r}^{2}>0.55\right)$ between $\mathrm{N}$-amount and SR (Figure 2).

When all events are combined (Event 1-5) the $\mathrm{r}^{2}$ is very low for all sward types $(<0.40)$ and biomass attributes (Tables 1 and 2).

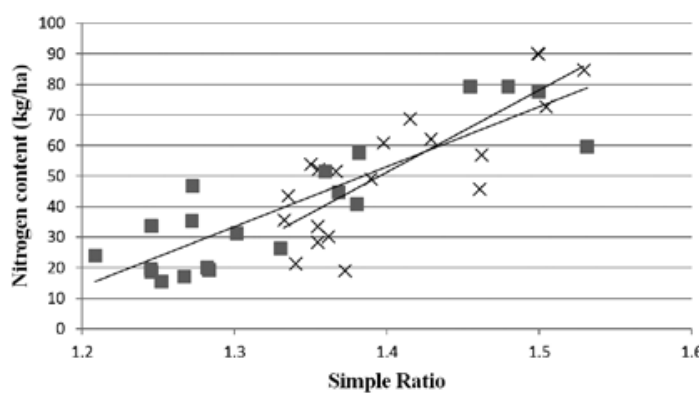

Figure 1 The relationship between dry matter and water index from measuring event 5 calculated with the RU-AOS. Measurements were taken on ryegrass only ( $\square)$ and mixed ryegrass and white clover swards $(x)$. $\left(r^{2}\right.$ for Combined swards $=0.80$; Mixed swards, 0.80 , Grass only 0.76 )

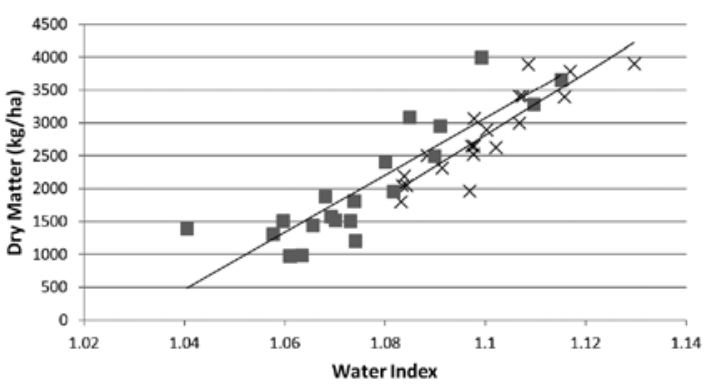

Figure 2 The relationship between nitrogen amount and simple ratio from measuring event 5 calculated with the RU-AOS. Measurements were taken on ryegrass only $(\boldsymbol{\square})$ and mixed ryegrass and white clover swards $(x)$. $\left(r^{2}\right.$ for Combined swards $=0.72$; Mixed swards, 0.66 , Grass only 0.76 )

Table 1 Relationship (as $\left.\mathrm{r}^{2}\right)$ between biomass dry matter amount $(\mathrm{kg} / \mathrm{ha})$ and water index from each monitoring event for ryegrass only swards (Ryegrass); mixed ryegrass and white clover swards (Mixed); and combined sward types (Combined).

\begin{tabular}{lcccccc}
\hline Sward type & \multicolumn{3}{c}{ Event } & $\mathbf{4}$ & $\mathbf{5}$ & $\mathbf{1}$ \\
\hline Ryegrass $(\mathrm{n}=20)$ & $\mathbf{1}$ & $\mathbf{2}$ & $\mathbf{3}$ & 0.5 & 0.76 & 0.15 \\
Mixed $(\mathrm{n}=20)$ & 0.03 & 0.48 & 0.73 & 0.13 & 0.80 & 0.13 \\
Combined $(\mathrm{n}=40)$ & 0.00 & 0.33 & 0.14 & 0.43 & 0.15 \\
\hline
\end{tabular}

Table 2. Relationship (as $\left.\mathrm{r}^{2}\right)$ between biomass nitrogen amount $(\mathrm{kg} / \mathrm{ha})$ and simple ratio index for each monitoring event for ryegrass only swards (Ryegrass); mixed ryegrass and white clover swards (Mixed); and combined sward types (Combined).

\begin{tabular}{lcccccc}
\hline Sward type & \multicolumn{3}{c}{ Event } & $\mathbf{4}$ & $\mathbf{5}$ & $\mathbf{1}$ \\
\hline Ryegrass $(\mathrm{n}=20)$ & $\mathbf{1}$ & $\mathbf{2}$ & $\mathbf{3}$ & 0.89 & 0.76 & 0.39 \\
Mixed $(\mathrm{n}=20)$ & 0.63 & 0.56 & 0.68 & 0.69 & 0.66 & 0.12 \\
Combined $(\mathrm{n}=40)$ & 0.23 & 0.16 & 0.48 & 0.81 & 0.72 & 0.27 \\
\hline
\end{tabular}




\section{Sensitivity of reflectance measurements to sensor angle}

The ANOVA for the WI showed that the view angle had a highly significant influence $(\mathrm{P}<0.001)$ on the reflectance data. There was also a significant influence of the interaction between the angle and fertiliser amount factors $(\mathrm{P}<0.05)$. Other factors and their interactions were not found to significantly influence WI.

The ANOVA for the SR showed that all three factors; angle, fertiliser and sward independently have a significant influence on the levels of SR $(\mathrm{P}<0.001)$. There were no significant influences from interactions of these factors.

\section{Discussion}

\section{Dry matter and $\mathrm{N}$-amount monitoring}

Linear regressions have a high $\mathrm{r}^{2}$ for the WI and biomass DM on the grass only swards. There was only one occasion where $r^{2}$ values were above 0.5 for the mixed sward and combined sward types. Thus, the WI appears to be more applicable to a wider range of situations in a predominantly ryegrass only canopy. Mono-species grass pasture swards have successfully been monitored by AOS systems for estimating biomass attributes (Pullanagari et al. 2011; N\%; $\mathrm{r}^{2}=0.76$ ); Trotter et al. 2010 (green DM; $\left.\mathrm{r}^{2}=0.80\right), 2012\left(\right.$ green DM; $\left.\mathrm{r}^{2}=0.91\right)$. Trotter et al. (2010) used cross-validation techniques to estimate the error of prediction for the spectral indices investigated in their research. Unfortunately, due to small sample sizes for each linear regression calculated $(n=20)$, this data was not able to be investigated using that method. However, on one event the mixed sward $\mathrm{DM}$ and WI did produce a high $\mathrm{r}^{2}\left(\right.$ event $=5, \mathrm{r}^{2}=0.80$ ). This promising result suggested that the sensing system could be used in assessing the canopy characteristics for decision making purposes, although determination of prediction error was not possible.

For event 5 (Figure 1) the linear regressions for DM and WI resulted in an $\mathrm{r}^{2}$ of above 0.75 for each sward type and combination. Remarkably, unlike all other events (Table 1 ), grass only swards showed a slightly lower $r^{2}$ than the mixed swards. This was unexpected as the presence of clover typically appears to corrupt the results.

In the same manner as the relation of WI to DM, the SR measured by the RU-AOS showed a stronger correlation to $\mathrm{N}$-amount for the ryegrass only swards. All events (independently) resulted in an $\mathrm{r}^{2}$ above 0.55 , suggesting the relationship between pure swards and reflection is simpler.

Higher correlations were present between SR and $\mathrm{N}$-amount than WI and DM. This suggested that plant reflectance related to $\mathrm{N}$-amount was more consistent than DM across the two plant species and there is a stronger influence of the nitrogen amount on the optical reflectance characteristics. Additionally, there were more linear correlations of sufficiently high determination (events) for the grass only swards than the others. Therefore, this AOS appears more suited to uniform swards.

\section{Sensitivity analysis}

The ANOVA test found a significant effect of angle on the reflectance indices as well as an interaction effect of angle and nitrogen fertiliser on WI. Despite the significant relationship between the angle and index values, this does not seem to transfer to the relationship between index values and biomass. This was unable to be tested statistically due to a lack of data $(n=20$ per event for each sward type). Therefore, the regression equations of the WI and biomass datasets were compared and found to have little practical difference. As such, any specific angle was unable to be proven as providing a more accurate result than any other angle.

\section{Summary}

Initial relationships between the RU-AOS and pasture attributes are encouraging. Calibration equations for estimating DM and $\mathrm{N}$-amount using the RU-AOS need to be further developed. Following this step, the error of prediction should be determined to investigate the success and compare the sensor to other situations (i.e. arable crops) and other techniques currently in use. Additionally, an investigation of the cause of variation between events is required. Previous research has indicated that a higher proportion of senescent biomass in a sward may result in a poorer relationship (Trotter $e t$ al. 2012); however in this research weak relationships do not align consistently by sward or to periods of expected high senescent material.

The sensitivity study determined sensor angle (40 or 55 degrees) influenced the index values. However, it did not determine which angle produced the most accurate biomass correlation. As such the sensitivity analysis cannot be used to explain the results of the canopy study. Further research should be undertaken to investigate the accuracy of biomass estimation when using variable angles.

The results indicated that there is a stronger relationship to homogenous grass swards. This is not surprising as the spectral response of different species is likely to be different (Shenk et al. 1979). In order to take advantage of this observation, it is proposed that the clover content of a mixed sward could be estimated by incorporating machine vision and developing a clover correction factor based on the results of a clover estimator. Future work will investigate the potential to accurately correct nitrogen and biomass estimates with a calculated clover correction factor.

A first investigation with the RU-AOS showed the biomass attributes $(\mathrm{DM}, \mathrm{N})$ are related to the derived 
indices (WI, SR). This is a promising start and further research could lead to the use of this tool for estimating $\mathrm{N}$-status of pastures and direct $\mathrm{N}$-fertiliser VRA.

\section{ACKNOWLEDGEMENTS}

This research is funded by the Ministry of Business, Innovation and Employment of New Zealand (contract No.: CONT-29854-BITR-LVL). Project collaborators include: Massey University, AgResearch, Lincoln University and the University of New England (Australia).

\section{REFERENCES}

Barnes, P.; Wilson, B.R.; Trotter, M.G.; Lamb, D.W.; Reid, N.; Koen, T.; Bayerlein, L.; 2011. The patterns of grazed pasture associated with scattered trees across an Australian temperate landscape: an investigation of pasture quantity and quality. The Rangeland Journal 33: 121-130.

Bragagnolo, J.; Carneiro Amado, T. J.; da Silveira Nicoloso, R.; Jasper, J.; Kunz, J.; de Grefori Teixeira, T. 2013. Optical crop sensor for variable-rate nitrogen fertilisation in corn: I - plant nutrition and dry matter production. Brasilian Journal of Soil Science 37: 1288-1298.

Erdle, K.; Mistele, B.; Schmidhalter, U. 2011. Comparison of active and passive spectral sensors in discriminating biomass parameters and nitrogen status in wheat cultivars. Field Crops Research 124: 74-84.

Heege, H. J.; Reusch, S.; Thiessen, E. 2008. Prospects and results for optical systems for site-specific onthe-go control of nitrogen-top-dressing in Germany. Precision Agriculture 9: 115-131.

Holland, K. H.; Schepers, J. S. 2013. Use of a virtualreference concept to interpret active crop canopy sensor data. Precision Agriculture 14: 71-85.

Jackson, T. J.; Chen, D.; Cosh, M.; Li, F.; Anderson, M.; Walthall, C.; Hunt, E. R. 2004. Vegetation water content mapping using Landsat data derived normalized difference water index for corn and soybeans. Remote Sensing of Environment 92: 475-482.

Jasper, J.; Reusch, S.; Link, A. 2009. Active sensing of the $\mathrm{N}$ status of wheat using optimized wavelength combination: impact of seed rate, variety and growth stage. Precision Agriculture 9: 23-30.

Jordan, C.F. 1969. Derivation of leaf-area index from quality of light on the forest floor. Ecology 50: 663666.

Kim, Y.; Glenn, D. M.; Park, J.; Ngugi, H. K.; Lehman, B. L. 2012. Characteristics of active spectral sensor for plant sensing. Transactions of the ASABE. American Society of Agricultural and Biological Engineers 55: 293-301.

Kipp, S.; Mistele, B.; Schmidhalter, U. 2012. Active sensor performance-dependence on measuring height, device temperature and light intensity. pp. 15-18. In: Proceedings of the 11th International Conference on Precision Agriculture.

Link, A.; Panitzki, M.; Reusch, S.; Robert, P.C. 2003. Hydro N-Sensor: tractor-mounted remote sensing for variable nitrogen fertilization. pp. 1012-1017. In: Proceedings of the 6th International Conference on Precision Agriculture and Other Precision Resources Management of American Society of Agronomy.

Malcolm, B.J.; Cameron, K.C.; Di, H.J.; Edwards, G.R.; Moir, J.L. 2014. The effect of four different pasture species compositions on nitrate leaching losses under high N loading. Soil Use and Management 30: 58-68.

McCall, D. G.; Clark, D. A. 1999. Optimized dairy grazing systems in the northeast United States and New Zealand. II. System analysis. Journal of Dairy Science 82: 1808-1816.

Penuelas, J.; Pinol, J.; Ogaya, R.; Filella, I. 1997, Estimation of plant water concentration by the reflectance Water Index WI (R900/R970). International Journal of Remote Sensing 18: 2869-2875.

Portz, G.; Molin, J. P.; Jasper, J. 2012. Active crop sensor to detect variability of nitrogen supply and biomass on sugarcane fields. Precision Agriculture 13: 33-44.

Pullanagari, R. R.; Yule, I.; King, W.; Dalley, D.; Dynes, R. 2011. The use of optical sensors to estimate pasture quality. International Journal on Smart Sensing and Intelligent Systems 4: 125-137.

R Core Development Team. 2015. R: A language and environment for statistical computing. $\mathrm{R}$ foundation for Statistical Computing, Vienna, Austria. URL http://www.R-project.org/ Accessed: 1 June 2015.

Roberts, D.F.; Adamchuk, V.I.; Shanahan, J. F.; Fergason, R.B.; Schepers, J.S. 2009. Optimisation of crop canopy sensor placement for measuring nitrogen status in corn, Agronomy Journal 101: 140-149.

Shenk, J.S.; Westerhaus, M.O.; Hoover, M.R. 1979. Analysis of forages by infrared reflectance. Journal of Dairy Science 16: 807-812.

Stone, M.L.; Duane, N.; Solie, J.B.; Raun, W.R.; Johnson, G.V. 2003. Optical spectral reflectance sensor and controller. U.S. Patent No. 6,596,996

Trotter, M.G.; Lamb, D.W.; Donald, G.E.; Schneider, D.A. 2010. Evaluating an active optical sensor for quantifying and mapping green herbage mass and growth in a perennial grass pasture. Crop and Pasture Science 61: 389-398.

Trotter, M.; Lamb, D.; Schneider, D.; Edwards, C.; McPhee, M.; Falzon, G. 2012. Examining the potential for active optical sensors to provide biomass estimation in improved and native pastures. $I n$ : the Proceedings of the 16th Australian Agronomy Conference. 
Verzani, J. 2014. Using R for introductory statistics.

CRC Press.

Yule, I, Pullanagari, R 2009. Use of reflectance sensors to optimise nutrient management. Nutrient Management in a Rapidly Changing World.

Occasional Report No. 22: 70-79. 